\title{
À Flor da Pele: Uma cartografia da subjetividade docente em Ciências
}

Thiago Ranniery Moreira de Oliveira ${ }^{1}$

Livia de Rezende Cardoso ${ }^{2}$

\section{Resumo}

Em uma inusitada viagem ao mundo da subjetividade docente em Ciências, este artigo empreende uma cartografia de processos de subjetivação docente em Ciências nas disciplinas da área de Ensino de Ciências ofertadas no Curso de Licenciatura em Ciências Biológicas da Universidade Federal Sergipe para investigar como se faz viver a docência em Ciências, os critérios com os quais ela se inventa como aquilo que ela é. Desenvolve, assim, o argumento de que o estatuto de verdade da Ciência e do discurso pedagógico do Ensino de Ciências situam o professor de Ciências como uma figura de ficção messiânica, uma figura mirante, que entra em colapso no contato com a potência criativa do Outro Aluno. Explorar, deste modo, a potencialidade da composição transmigração da docência em Ciências, visto que jamais compreenderemos porque devemos passar a vida inteira usando a mesma pele.

Palavras-chave: formação de professores, docência em Ciências, subjetividade, ilusão, transmigração.

1 Doutorando em Educação pela Universidade do Estado do Rio de Janeiro (Proped/ UERJ). Email: t.ranniery@gmail.com.

2 Doutorado em Educação. Professora do Departamento de Educação da Universidade Federal de Sergipe (DEDI/UFS). Email: livinha.bio@gmail.com. 


\title{
Far too sensitive: a mapping of Science in teaching subjectivity
}

\begin{abstract}
In an unusual journey into the world of subjectivity in science teaching, this article undertakes a mapping processes of subjectivity in science teaching in the disciplines of Science Education offered in the Biological Sciences Graduate, Federal University Sergipe to investigate how to make live teaching of Science, the criteria with which she invents for what it is. Thus, it developed the argument that the statute of true of Science and the pedagogical discourse of Science Teaching situated Professor of Science as figure of messianic fiction, a figure lookout, which collapsed in touch with the creative power of Another Student. Explore, therefore, the potential composition transmigration of teaching in science, since never understand why we spend a lifetime using the same skin.
\end{abstract}

Key-words: teacher training, teaching in science, subjectivity, illusion, transmigration.

\section{Esboço de uma viagem}

Damos início, aqui, a uma inusitada viagem ao mundo da subjetividade docente em Ciências, com uma especial curiosidade em conhecer os embates nas regiões fronteiriças da pele da docência em Ciências. Compartilhamos, aqui, uma cartografia da subjetividade docente em Ciências, por certo, sempre provisória, aberta e indefinida, de um currículo de formação de professores de Ciências, especificamente nas disciplinas Metodologia da Pesquisa Biológica I, Fundamentos de Ensino-Aprendizagem em Ciências e Biologia e Estágio em Laboratório de Ensino ofertadas no Curso de Licenciatura em Ciências Biológicas da Universidade Federal Sergipe. As práticas de ensino ou as chamadas 
disciplinas pedagógicas ${ }^{3}$ das licenciaturas são, aqui, escolhidas, justamente, por serem aquelas nas quais os alunos entram em contato com os discursos pedagógicos do Ensino de Ciências. Porém, se, de algum modo, pudéssemos resumir os mais variados estudos sobre a formação de professores de Ciências e Biologia, vislumbraríamos, um tanto distraídos, a emergência de necessidade de um novo perfil profissional (FREITAS; VILLANI, 2002), capaz de localizar os desafios mais urgentes da aldeia global. Sem muita dificuldade, logo notaríamos que a densidade desta pele é ilusória e que efêmero é o perfil que ela envolve e delineia.

Com efeito, existe uma farta produção acadêmica sobre a formação de professores no Brasil (ANDRÉ, 2002), de tal forma que esse campo de conhecimento já foi mesmo caracterizado como em "estado de ebulição" (MEDEIROS, 2005). 0 campo destinado à formação de professores de Ciências e biologia também não parece ser carta fora desse baralho e tem ocupado parte significativa das pesquisas em Ensino de Ciências e Biologia (TARDIF; MEGID NETO, 2007). Todavia, parece ser necessário o investimento na incorporação de outras linhas teóricas para ampliar as análises sobre constituição da identidade e da profissão docente (LUDKE; BOING, 2004). Nesse sentido, se há um tema que surge com vigor é aquele descrito sob a expressão de "aprender a ensinar", os processos pelos quais os professores geram conhecimento, além de sobre quais tipos de conhecimentos adquirem (GARCIA, 1998). De certo, se o que está em jogo são os processos pelos quais os professores adquirem certos conhecimentos

3 Ao optarmos pela denominação disciplinas pedagógicas, não estamos desconsiderando que as demais disciplinas de um currículo de formação de professores de Ciências e Biologia não são pedagógicas. Ao contrário, partimos do pressuposto que todos os espaços de um currículo são pedagógicos. No entanto, esse modelo de currículo que separa "conteúdos educacionais" e "conteúdos específicos da Biologia" é o modelo adotado pelo curso de Licenciatura em Ciências Biológicas da Universidade Federal de Sergipe. Quando optamos por denominar disciplinas pedagógicas é apenas para reforçar que é predominantemente nessas disciplinas que as discussões sobre Ensino de Ciências e Biologia são postas para os alunos. 
e saberes na sua formação, podemos pôr em discussão com Michael Foucault (1986) que a constituição desses saberes e de seus campos só existem em relações de poder e que é por meio dessas relações de poder-saber que são engendrados processos de subjetivação através dos quais os professores são erguidos e maquinados como professores de certo tipo.

No entanto, as práticas curriculares convencionais, presas como estão em paisagens extremamente tecnicistas e estéreis, raramente permitem que sejam feitas questões além daquelas relacionadas com utilidade, competência ou medição (KLIEBARD, 1992; HARTLEY, 1997). Geram uma espécie de espaço pré-fabricado que tende a ser estéril, uma vez que a percepção, no seu interior, continua sob o domínio da profunda superstição platônica da mente concebida como um espelho que reflete a realidade (RORTY, 1979). Nosso empreendimento consiste, por outro lado, pôr em discussão os modos de subjetivação em um curso de formação de professores de Ciências, os processos através do quais professores constituem um determinado tipo de relação consigo mesmo; o modo pelo qual se produz um Dentro do Fora (DELEUZE, 2006). Como uma dobra das forças de Fora, a subjetividade é uma invaginação através da qual se cria um interior. A subjetividade docente não escapa as forças poderosas e as estratégias insuspeitadas que desenham o rosto, mesmo que incerto, do professor de Ciências. 0 argumento, aqui, defendido é que o estatuto de verdade dos discursos pedagógicos do Ensino de Ciências e do discurso científico, quando circulam em sala de aula aliados a outros discursos, expressam certos modos de subjetivação específicos, dobrando e desdobrando, a docência em ciência. A análise empreendida, em nossa perspectiva, se refere, em última instância, tanto a como se faz viver a docência em Ciências nos currículos de formação de professores, quanto à escolha dos critérios com os quais ela se inventa.

Entendemos, nesse sentido, que "numa cartografia, pode-se apenas marcar caminhos e movimentos, com coeficientes de 
sorte e de perigo. É o que chamamos de 'esquizoanálise', essa análise das linhas, dos espaços, dos devires” (DELEUZE, 1992, p.48). Inventada por Deleuze e Guattari (1977, 1997a, 1997b), a cartografia é comumente empregada nos estudos de campo para o acompanhamento dos processos de subjetivação. Não há subjetividade sem uma cartografia que lhe sirva de guia. Reciprocamente, não há cultura sem certo modo de subjetivação que funcione segundo seu perfil (ROLNIK, 1989). Transportada para a pesquisa em Educação", a cartografia parece soar como "uma espécie de tecnologia de reconsideração das significações dominantes" (GUATTARI, 1988, p. 175) dos fazeres da pesquisa em educação para permitir pôr em deslocamento as formas lineares e unívocas da pesquisa científica e assumir-se implicada na criação de outros modos de existência. Cartografar um currículo é, pois, construir um mapa aberto dos seus segmentos, poderes e territórios, e dos seus pontos de desterritorialização, por onde um currículo foge e faz fugir (PARAÍSO, 2010). Ao recompor um mapa do currículo, aqui, investigado registramos um conjunto de linhas dispersas, funcionando todas ao mesmo tempo, "em velocidades variadas" (DELEUZE, 1992, p. 47). As linhas, elas mesmas, "são elementos constitutivos das coisas e dos acontecimentos" (DELEUZE; GUATTARI, 1992, p. 22) e, por isso mesmo, são constitutivas do currículo investigado e das subjetividades que ele produz e agencia.

Recorremos, aqui, a um exercício: vamos estender essa pele da docência em Ciências, desfazendo o perfil que ela desenha, de modo a transformá-la em um território plano. Recorremos, também para essa cirurgia dérmica da docência em Ciências, a conceitos retirados do pensamento da diferença para pensar nas pesquisas de formação de professores: o currículo menor (PARAÍSO, 2010). Aquele currículo que se realiza no cotidiano das 
salas de aula para irmos além do que e como ensinar/aprender em um currículo de formação de professores de Ciências e embarcarmos em como e o que se ensina e se aprende na docência em Ciências aflora na pele de professores de Ciências e Biologia, como este currículo funciona, que agenciamentos ele faz passar. Gallo (2002), inspirado em Deleuze e Guattari (1977) que pensam uma literatura menor, propõe pensarmos uma educação menor, aquela que se realiza no cotidiano de alunos e professores. Gauthier (2002) também coloca a importância do uso menor da pedagogia que "não pode outra coisa que não questionar às vezes até mesmo à sua revelia [...] a pedagogia maior" (GAUTHIER, 2002, p. 42). É esse sentido de investigar os agenciamentos, dobramentos e desdobramentos da subjetividade docente que acontecem no dia-a-dia de uma sala de aula de formação de professores, aquilo que aflora na pele de um professor de Ciências que essa escrita persegue.

\section{O Professor de Ciências jaz exilado...}

Aula de Metodologia da Pesquisa Biológica I, conhecida entre os alunos por "MPB". Dois grupos de estudantes são convidados a desenhar no quadro negro a pó de giz a construção do conhecimento em distintas épocas da história humana. Sol, lua, água da chuva, água de rio, fogo, raios, relâmpagos e trovoadas, caverna, rochas, árvores e seus frutos, peixes, pássaros e mamutes selvagens; varas de pescar, flechas, lanças e pedras lascadas. Mas, também, televisão, computador, microscópios, lupas, placas de petri, rádio, livro, antena, satélites, globos terrestres. Se de um lado, um homem de peito nu condensa em um só clímax a inocência e a aspereza da matéria da natureza, sem jamais subtrair uma da outra, permanece tacitamente como observador da realidade que se impõe naturalmente sobre ele. Do outro, um grande telescópio se põe entre o curioso olho do homem e a lua, agora já pequena diante dos nossos olhos tecnizados, enquanto 
um microscópio responde às perguntas que estão além da nossa pequena visão.

A visão, esse sistema sensorial, é evocada neste currículo para significar um salto para fora do corpo marcado. Um olhar que se inscreve miticamente sobre todos os corpos, que possibilita à categoria não marcada alegar ter o poder de ver sem ser vista, de representar, escapando à representação. 0 "olho que tudo vê" supera aquilo que é natural e é a evocação da tecnologia que opera esse efeito. A visão nesta festa tecnológica transforma-se numa glutonaria desregulada, onde todas as perspectivas cedem passagem a um modo que não se refere mais apenas a respeito do truque mítico de deus de ver tudo de lugar nenhum, mas da transformação do mito em prática comum (HARAWAY, 1995). Nessa espécie de momento poético e épico modernista, o jovem cientista passa horas debruçadas no microscópio, no qual as células parecem ser células e os organismos, os organismos. Nesta íntima relação entre ver e nomear o mundo, a Biologia nada mais é que a nomeação do visível (FOUCAULT, 1987). Mas não há olhar sem mediação de instrumento, seja ele, a palavra, a lupa, ou o microscópio. Afinal, "é o olhar que botamos sobre as coisas que, de certa maneira, as constitui” (VEIGA-NETO, 2002, p. 30). Sente-se, aí, o corpo padecer sem gosto, sabor ou odor, sem que seus pêlos se arrepiem ou que sua pele possa eriçar-se ao ser tocada - afinal, são imprecisões demais para serem aceitos como "cientificamente válidos". Para relembrarmos Foucault (1987), é preciso docilizar o corpo do professor-biológo-cientista para vincular seu olho e seu olhar a um lugar preciso. Do corpo excitável ao corpo manipulável, o olhar professor de Ciências não passa de um resíduo de onde tudo saiu, uma parda e fosca visibilidade, eterno glaucoma, estrabismo fatal que permite que qualquer coisa que ele descubra sobre terra se encaixe em seu lugar devido.

Afinal, a ciência é o certo e, por consequência, define o errado, sua prática é aquilo que divide. "Na busca da realidade, o cientista desvincula-se das crenças e pré-noções que a sociedade apregoa", 
escreve uma das alunas na atividade em que deveria definir "o que é Ciência?" Um modo de ser - de pensar, de agir, de sonhar, de amar, etc. - que recorta o espaço, formando um interior e um exterior. "Primeira regra para o uso correto da razão: [...] não se deixar levar pelas primeiras aparências" (VEIGA-NETO, 2002, p.26). Isso porque a Ciência nada mais é que "todo conhecimento através do qual se pode comprovar determinadas questões" - escreve um grupo de alunos. Seguros de sua posição como estudantes de Ciências Biológicas, suas definições são uma evocação do método e da experimentação. Reféns de uma concepção de moderna de Ciência fundada, o empirismo e o método cartesiano são aquilo que definem, por essência, o conhecimento científico. Suas peles são desenhadas para preencher uma unidade de Homem que se põe a serviço de uma razão única, universal e transcendental, enunciando o conhecimento científico como um porto de segurança no mar do irracionalismo da sociedade, objetivo diante da força de nossas emoções e metódico frente à algazarra de como levamos nossas vidas. Em face disso, o aprender é visto como recuperação de um mundo que existe lá fora, no qual o olho é ferramenta fundamental. À metáfora óptica da recuperação, podemos ainda acrescentar duas outras noçõeschave: a recognição e a representação.

Esse tríplice legado do platonismo e do cristianismo - visão, recoginação e representação - faz com que o mundo da experiência se conforme a um modele pré-dado de interioridade (ROY, 2002). As relações ópticas associadas com as ilusões transcendentais prestam-se à conformidade e à repetição, costurando uma pele sobre a qual só pode ser sustentada à ilusão da medição exata, da certeza e do controle. A invocação de uma visão óptica é tradução de um espaço curricular de formação de professores como um terreno muito mais regulado e governamentalizado. Em outras palavras, o currículo óptico pode estar associado com as necessidades centralizadas de um estado "panóptico" e com os imperativos de controle (FOUCAULT, 1987). Nesse continente, colonizado pela dominância 
da representação e da recognição, a suposta constância da espacialidade contribui para simplificar e reduzir as variáveis a parâmetros manipuláveis.

Esta relação entre metáforas óticas e ciência pressupõe também, por sua vez, uma correspondência material e uma relação não-mediada entre o "fora" e o "dentro", ente o "o sujeito" e o "mundo", um pressuposto binarista que tende a se mostrar facilmente insustentável. Formar o docente em Ciências começa a ser "o lugar da ilusão transcendental. Esta ilusão tem várias formas (...) que correspondem particularmente ao pensamento, ao sensível, á Idéia e ao ser" (DELEUZE, 1997, p. 420). A celebração da objetividade e de um obstinado compromisso com os fatos em nome da Ciência soa como uma inadvertida preparação para uma era da subjetividade radical (SENNETT, 1988). Subjetividade docente em Ciências que passa a ser "definida pelas exigências de uma visão distanciada: constância da orientação, invariância da distância por troca de referenciais de inércia, junção por imersão num meio ambiente, constituição de uma perspectiva central" (DELEUZE; GUATTARI, 1997, p. 205).

Ciência-vodu? Ciência-astrologia? Ciência-cartomante? Ciência-mãe-de-santo? Profetizando o futuro, esse discurso científico não somente anuncia o que se vai passar, mas contribui para sua realização, suscitando a adesão dos homens e se tramando como o único destino possível (FOUCAULT, 1986). A pele do professor de Ciências é dobrada para delinear o perfil de uma determinada figura da subjetividade, aquela subjetividade-cientista forjada na modernidade, que pôs o Homem de Ciência no lugar de um todo absoluto e poderoso, uma crença animada pelo desejo infinito de um humano que descobriu a inevitabilidade do fim. Entretanto, esse professor de Ciências jaz exilado, desamparado e só. Descobriu que o seu corpo adoece; que a sua razão esmorece ou se aliena; que o trabalho não sustenta a sua sobrevivência, que a sua linguagem não representa as coisas, como já discutiu Foucault (1999) - e como já nos expunha desesperadamen- 
te uma aluna estagiária do PIBID $^{5}$ o caos de sua sala de aula. É preciso partir para um disciplinamento moral do professor de Ciências, para sua humanização, para tirá-lo do limbo, que tão cedo, ele descobriu habitar.

Logo, nesse primeiro momento, e ainda no primeiro desenho da turma de MPB, chegamos também à sinuosa fronteira entre o animal e o homem. Uma travessia que nos parece despertar a verdade de que estamos muito perto do animal que nos constitui. “É muito tarde para negá-lo, ele terá estado aí antes de mim, que estou depois dele. Depois e perto do que chamam o animal e com ele - queiramos ou não, e o que quer que façamos da coisa" (DERRIDA, 2002, p. 29). Constrição que implica admitirmos que esse animal que, como homens olhamos, somos nós mesmos, "o animal que logo sou. Pois no fundo dos olhos desse animal ancestral está o espelho do homem, que se envaidece dele mesmo" (COSTA, 2008, p. 49). Nessa visão de uma época primitiva da nossa história, predomina uma verdade que toma a natureza selvagem como numa evocação mítica. Relação que pode ser vista tanto como uma separação da natureza quanto como uma volta a ela e, sobretudo, como uma relação de produção da natureza. "A natureza selvagem não demarcar a si mesmo, não se nomeia" (SACHAMA, 1996, p.17), seus significados são sempre resultados de experiências constituídas culturalmente. É através de negociações entre produção do humano e significação da razão que a forma subjetiva do professor de Ciências começa a ser maquinada em um currículo de formação.

5 Programa Institucional de Bolsa de Iniciação à Docência (Pibid) criado com a finalidade de oferecer bolsas para aprimorar a formação docente de estudantes de licenciatura plena, das instituições municipais, públicas e comunitárias. 
Quando o professor de Ciências é uma miragem...

Para seguirmos a nossa viagem, observamos agora que dentro e fora não são meras paisagens separadas por uma pele compacta que intenta delinear um perfil de uma vez por todas. Abandonemos, aqui, nosso exercício. Libertemos a pele, pois não nos é mais interessante mantê-la distendida para vermos as tatuagens do discurso científico. Deixemos, deste modo, a pele docente vibrar para acompanhar ao vivo o contorno de diferentes figuras da subjetividade docente em Ciências.

O discurso pedagógico do Ensino de Ciências tem ploriferado ataques aos cursos de formação de professores. Ora, as críticas referem-se à separação entre conhecimentos científicos e conhecimentos profissionais docentes; conhecimento acadêmico e realidade escolar; disciplinas específicas da área e disciplinas pedagógicas, ou entre formação científica e formação pedagógica (GARCIA; PORLAN, 2000; SCHÖN, 1983; 1995; NÓVOA, 1992; MARCELO, 1999; TARDIF, 2000). Ora, denunciam suas preocupações com os modos de mediação dos professores de disciplinas específicas, geralmente voltados somente para a transmissão de conteúdos da Biologia, desconsiderando as questões pedagógicas que os acompanham (CARRASCOSA, 1996; PAGOTTO, 1998; MALDANER, 2000; PEREIRA, 2000; SCHNETZLER, 2000). Se pudéssemos empreender um resumo, o que se tem é que ao final das disciplinas pedagógicas, os licenciandos serão capazes - deveriam ser, pelo menos - de promover "rupturas das visões simplistas sobre o ensino de Ciências", "conhecer a matéria ensinada", "questionar o senso comum sobre ensino e aprendizagem das Ciências", "adquirir conhecimentos teóricos sobre aprendizagem em Ciências", "saber analisar criticamente o ensino tradicional", "saber preparar atividades capazes de gerar uma aprendizagem efetiva", "saber dirigir o trabalho dos alunos, "saber avaliar", e "adquirir a formação necessária para associar ensino e pesquisa didática” (GIL-PÉREZ; CARVALHO, 2003). 
Sob a luz e força produtiva destes discursos, os licenciandos aportam nas disciplinas pedagógicas do Curso de Licenciatura em Ciências Biológicas. Aqui, eles aprendem a "desenvolver uma experiência a fim de produzir um novo conhecimento ou para corrigir e integrar novas idéias a conhecimentos pré-existentes", escreve um grupo de alunas em um Roteiro de Aula Experimental parte das atividades da disciplina Estágio em Laboratório de Ensino. Nela, alunos e alunas simulam uma aula experimental de Ciências, pois sabem que é "inconcebível um bom ensino de Ciências sem atividades práticas, sem experimentação" (MORAES, 1998, p. 29), pois tem "o objetivo de ilustrar uma teoria" (AZEVEDO, 2004, p. 25), tornando-se, assim, "um dos bons caminhos para concretização da aprendizagem" (ROCHA FILHO et al., 2007, p. 225). Entende que este se configura como o momento de "testar algo, de pôr algo à prova" (MORAES, 1998, p. 30). É um espaço "aberto à experiência controlada” (WEISSMANN, 1998, p. 232), cujo resultado consiste na obrigação dos alunos em "rever o que pensam sobre um determinado fenômeno ao colher dados que não confirmam suas crenças anteriores" (BIZZO, 1998, p. 75). Nessa dinâmica da aula, "para as atividades práticas darem o melhor resultado possível, o comportamento de professores e alunos deve ser estruturado" (KRASILCHIK, 2004, p. 126).

0 roteiro a ser seguido na aula experimental, distribuído pelos futuros professores aos alunos simulados ${ }^{6}$, está sob a ameaça de ser perturbado por um conjunto dinâmico de universos que podem atravessar uma aula de Ciências. É difícil lidar com aquilo que põe o roteiro em um movimento de fuga sem fim. A figura da subjetividade mirante do professor de Ciência entra em colapso no contato com a potência criativa do aluno, enquanto Outro, enquanto aquele que chega à sala de aula indubitavelmente sem

6 Como parte de uma das unidades avaliativas previstas na disciplina de Laboratório de Ensino de Ciências, os alunos, divididos em grupos, executam uma aula experimental de Ciências para uma determinada série, situação na qual os demais alunos e, inclusive, a própria professora da disciplina, simulam alunos da série escolhida pelo grupo. 
convite. 0 que pode, especialmente, fazer o experimento "dar errado" e o professor "não saber o que fazer" quando a tragédia parece anunciada. "Se era uma aula experimental, o experimento deveria dar certo!" - pronuncia a aluna ao ver seu experimento sobre tipos de solos simplesmente falir. Como é que se explica que o maior medo de uma professora de Ciências seja exatamente em relação ao "erro"? 0 currículo transcendental individualizante e formador de ficção de humanidade divulga uma espécie de inconveniência com o "erro", com aquilo que "não é", traduzido sob o sentimento do medo. Como bem destacou Delumeau (2009), o medo atua justamente impelindo ou bloqueando ações, desejos e pensamentos em determinada configurações históricas.

Contudo, como se explica que o maior medo seja exatamente o de ir vivendo o que for sendo? Como é que se explica que um "eu-professor-de-Ciências” não tolere o caos, só porque a vida não é o que pensava e sim outra coisa, como se antes tivesse sabido o que era? Sobretudo, será possível a existência desse professor de Ciências? Obviamente ele nunca chega lá, já que esse "lá" é, em qualquer caso, uma miragem. Parece impossível ser este professor-miragem impelido pelo discurso pedagógico da formação docente, ao mesmo tempo, em que se serve a rota discursiva da Ciência, porque se está sujeito à sorte e ao perigo do formar-se. 0 que se percebe é que o território do Ensino de Biologia parece estar sujeito a um permanente movimento de desterritorialização (AMORIM, 2000; 2004). Um currículo de formação de professores passo, por certo, a ser um território que demanda e convoca distintas e conflitantes posições de docência em Ciências.

Ao considerarmos "o currículo nos produz" (SILVA, 1999), isto é, sua força de produção e ação da vida, a sala de aula de formação de professores pode ser pensada como uma série de "conjuntos de arranjos e práticas no interior dos quais várias formas de imagens, som, texto e fala são construídos e apresentados e com as quais, ademais, interagimos e que estão implicadas na produção de significados que dão às pessoas uma idéia de quem elas são e de quais 
serão seus futuros" (SIMON, 2008, p. 71). A questão é, neste currículo, instaura-se uma miragem de professor que paira acima das turbulências da sala de aula, que aprende não só "as habilidades consideradas adequadas a essa/e profissional, mas também os procedimentos que esse sujeito deve ter na vida, como deve ser a sua conduta, que tipo de pessoa deve ser" (PARAÍSO, 2006, p. 95). Uma miragem que tende a convocar formas de se produzir como professor pautada, paradoxalmente, em uma experiência messiânica das Ciências, cultuada nos templos da Universidade e mantida pela doutrina dos saberes pedagógicos. 0 professor de Ciências passa a ser uma ficção messiânica, uma ilusão pedagógica, inventada por um humano carente de estabilidade, incapaz de suportar as vertigens da desestabilização, aquela inquietação que agita sua pele, como se algo estivesse fora do lugar. Cada modo de existência conferido no currículo aqui investigado - seja pelo discurso científico seja pelo discurso pedagógico da formação de professores em Ciências - é uma dobra da pele que delineia o perfil de uma determinada figura da subjetividade docente em Ciências.

\section{Narcóticos: alimentos da ilusão pedagógica}

Chamaremos de "narcotráfico pedagógico" a proliferação cada vez mais intensa no Ensino de Ciências de procedimentos, metodologias e técnicas que sustentam e produzem esta demanda de ilusão, promovendo uma espécie de mania toxicólogica generalizada. Contudo, a que drogas, estamos nos referindo? No mercado de narcóticos legalizados do Ensino de Ciências não faltam "Experimentação”, "Contextualização", "Ensino por investigação", “Técnica da Redescoberta”, "Técnica do Problema”, "Ensino por projetos", "Lúdico", "Construtivismo", “CTS”, "Tecnologias da Informação e Comunicação”. Um vício considerado politicamente correto, com amplo respaldo social, que permite reivindicar para si a identidade de um professor "reflexivo" (SCHÖN, 1995), "pesquisador" e "dialético" (VAZQUEZ, 1968). Os currículos de formação de professores, ou pelo menos o currículo, aqui, inves- 
tigado, é um mundo de transcendências, é sempre este e aquele mundo. E é também um mundo de indivíduos, onde só se conta este licenciando ou aquela licencianda incorporou este ou aquele narcótico nas suas aulas.

Por um lado, esta divulgação de narcóticos na formação de professores de Ciências tende a produzir um mundo onde dizer e ser "eu", ser um tipo de professor, torna-se cada vez mais importante. Um currículo, assim, implicado, por lado, na produção de certo tipo de eu-professor-de-Ciências, é também a casa do ruim e do bom, permanentemente preocupada em saber se contribui para um mundo melhor ou pior. Um currículo de formação que supõe e afirma uma ontologia moralizante, transcendente, individual (KOHAN, 2002). O professor de Ciências parece encarnar algo de "pastor", de um exercício de um poder pastoral, novamente retomando Foucault (2008). Isso porque, ao final de algumas contas, o professor de Ciências será aquela capaz "de permitir que os indivíduos avancem e progridam no caminho da salvação" (FOUCAULT, 2008, p. 211). Se aqui, vive-se no reino dos dualismos, do ser ou não ser, dos modelos, da disciplina, do controle, vive-se o modelo do salvar-se e do ser salvo.

É notável que não se deixa de carregar o livro didático para onde quer que se for nesse empreendimento. Na aula em que são solicitados a construírem um plano de aula, alunos e alunas transformam os tópicos dos livros didáticos em conteúdo programático das aulas de Ciências. Desesperam-se ante a escrita do procedimento metodológico - professora, o que quer dizer isso mesmo? Perdem-se diante da avaliação da própria aula - ao final da aula será aplicado um exercício para saber o que os alunos aprenderam. Entretanto se o conhecimento, hoje, é aquele construído nos e pelos aparelhos tecnológicos como bem destacaram esses alunos em seus desenhos, porque ainda lá, entre a tv, o computador e o satélite, não se deixar figurar o entre os desenhos, o Livro e Scientific American? Eles, os livros científicos, são as fontes de um saber institucionalizado. 
Aqui, ainda temos uma fronteira a ser desterritorializada: os formatos em que o conhecimento científico está autorizado a transitar. Machado (1997) recorda que a idéia de que o conhecimento é um saber de livros é uma noção da época moderna, provavelmente derivada da distinção medieval entre clérigos e leigos. 0 caráter uniformizador e seriado introduzido no ocidente pela imprensa de Gutenberg retomam como nossas instituições intelectuais "ainda parecem se deixar embalar pelas idéias esdrúxulas de que o conhecimento se encontra associado exclusivamente ao modelo conceitual do texto impresso ou de que só se pode pensar com palavras, com palavras escritas preferencialmente" (MACHADO, 1997, p. 178). Abraçam-se com louvor todas as transformações engendradas no mundo contemporâneo que ressaltam os "avanços da Ciências", mas parece ser ainda muito cedo para renunciarmos a certas práticas de Educação em Ciências do passado.

Contudo, nas micro-aulas e nos relatórios sobre as visitas que fazem a escolas públicas e particulares da rede educacional, os alunos consomem altas doses de "novas tecnologias". Como todo remédio contra o desamparo humano, também este da ilusão tecnológica pode ser visto como um indecidível, ao modo do pharmacon platônico, relido por Derrida (1991), ou seja, ao mesmo tempo, como remédio e veneno. Só que, em função de sua porção venenosa, talvez, hoje, estejamos migrando da ilusão ao delírio-das-novas-tecnologias. Uma espécie de coma induzido se instaura diante de qualquer tecnologia que possa soar mais atrativa que o enfadonho quadro negro e giz. É comum os alunos solicitarem data-shows para as aulas simuladas com a justificativa de torná-las dinâmicas. Neste instante, não há como não retomar o desenho dos alunos de MPB e sua sala de aula com um telão projetando a figura do professor para alunos disciplinarmente sentados. Aulas dinâmicas? Cinematográficas? Virtuais? Ou estamos apenas trocando o quadro negro pelo data-show? 0 giz pelas teclas up, down, left e right dos lap tops e pcs? Seria preciso se perguntar quando e como "a sala de aula tradicional" foi inventada como sinônimo do quadro negro e giz em contra posição "a sala de aula moderna" da tecnologia visual. 
Ampliando incertezas, implodindo ilusões...

Com efeito, todas as ilusões falham. Com efeito, o professor de Ciências de hoje des-ilude. Porém, é difícil constatar esse seu caráter ilusório, mirante, dérmico. Como fazer do professor de Ciências um objeto de questionamento, se ele é o cientista moderno que figura dentro da Escola? Como problematizar essa figura de subjetividade, que só deve ser protegida, fortalecida e desenvolvida pela universidade para saber e saber fazer? Como criticar o Professor/a de Ciência, se ele/a faz o mundo mais crítico e torna a vida mais digna de ser vivida, iluminando aquilo que se encontrava obscuro? Como desconstruí-lo, se a academia tem nos legado provas da sua efetividade? Como aceitar que é coisa fabricada por nós, movidos apenas por razões humanas, demasiado humanas?

Quando, na atualidade, uma heterogeneidade de práticas discursivas tem se endereçado à docência contemporânea, acreditar que a pele docente em ciência só estará figurada pelas rotas discursivas da Ciência e da Pedagogia do Ensino de Ciências também nos parecer ser uma ilusão que fadada ao fracasso. Logo, observamos que outros fluxos vão entrando na composição da pele, formando as mais diversas constelações que vão se acumulando até que um diagrama inusitado de relações de força se configure e que, aos poucos, outros diagramas de relações de força emergem e assim sucessivamente. 0 que sabemos é que há "uma ampliação dos lugares em que nos informamos, em que de alguma forma aprendemos a viver, a sentir e a pensar sobre nós mesmos" (FISCHER, 1997, p. 62). As/os professoras/es são pensadas/os de diferentes modos, em diferentes espaços e por discursos de diferentes tipos (PARAÍSO, 2007). Outros espaços culturais: a mídia e sua política de subjetividade docente (PARAÍSO, 2005, 2006, 2007), o cinema e a identidade da docência (SIQUEIRA et al, 2005, AMORIM, 2006), e as próprias políticas governamentais de formação docente (BALL, 2005; SANTOS, 2004) permitem "aos indivíduos efetuarem certo número de 
operações sobre seus corpos, (...) , sobre seu próprio pensamento, sobre sua própria conduta, e isso de tal maneira a transformarem-se a eles próprios, a modificarem-se, ou a agirem num certo estado de perfeição" (FOUCAULT, 1993, p. 207).

Por efeitos de nossas próprias práticas culturais, era comum vermos os alunos do nosso curso de formação de professores assumirem salas de aulas em escolas particulares ainda no início do curso. Aqui, eles têm hora para entrar e sair, prazos a cumprir, conteúdos a dar, provas e simulados para corrigir, são pressionados por papais e mamães, por coordenadores e diretores. Cães-de-guarda dessa figura da docência-funcionária que recorta a pele para "anular os efeitos das repartições indecisas, o desaparecimento descontrolado dos indivíduos, sua circulação difusa, sua coagulação [...] perigosa; tática de antideserção, de antivadiagem, de antiaglomeração para poder a cada instante vigiar o comportamento de cada um [...] medir as qualidades ou os méritos" (FOUCAULT, 1987, p.131). Os currículos não só jogam com alunos, mas as intensas emoções de professores também são submetidas a uma espécie de ilusão-funcionalista que imprime um decalque narcisista para o qual a fama entre os alunos da cidade é a droga da vez. Narcisismo que está longe da idéia popular de amor pela própria beleza, é mais uma preocupação de si consigo mesmo, de ser e poder dizer "sim, eu sou bom professor" - tanto para a Ciência, tanto para o Ensino de Ciências, tanto para a Escola - que nos impede de entender que isso, supostamente inerente ao domínio do eu, que depende exclusivamente do "meu talento", da "minha simpatia" com os pais e alunos compõe os modos pelos quais forças e poderes são dobrados, introjetados como parte de um modo de tornar-se sujeito professor de Ciências.

Mais do que se esmagar a subjetividade docente, a arquitetura escolar produz a possibilidade de que os professores, humanos, se relacionem consigo mesmos e com os outros como sujeitos de certo tipo (PARAÍSO, 2006; ROSE, 2001), bem como as possi- 
bilidades de que resistam ou rejeitem certos regimes de subjetivação. Essa subjetividade, porém, não cessa de ser arrancada do solo na sala de aula do curso em licenciatura. 0 estranhamento toma conta da cena: desestabilizados, desacomodados, desaconchegados, desorientados. Nos momentos em que ainda lhe resta alguma esperança de permanecer na mesma dobra, eles procuram restabelecer sua ilusória identidade que os novos diagramas vieram abalar. Neste caso, apelam para fórmulas mágicas de toda espécie: de tecnologias educacionais a dinâmicas de grupo.

A teologia bem aventurada da continuidade e do progresso científico, cultuada no Ensino de Ciências, talvez não seja mais realizável. "desinteresse dos alunos", "descontextualização", "fragmentação”, “dtilitário”, políticas de Pluralismo Epistemológico, que traçam geografias multiculturais e lógicas de concepções prévias e alternativas, recitam alfabetos científicos, desenham estéticas do meio ambiente, declinam sintaxes de TIC's. E alunos e alunas sentem-se inseguros, decepcionados, tristes, melancólicos, ansiosos, culpados, deprimidos, estressados, em pânico, moribundos, quase zombies após o término das micro-aulas como parte das atividades de Fundamentos de Ensino-Aprendizagem de Ciências e Biologia e Estágio em Laboratório de Ensino. É como se a pele-docente estivesse definhando. E quanto mais se frustram, mais correm atrás; e quanto mais desorientados, mais eles se drogam. Um círculo vicioso infernal. São tantas as demandas sobre os/as professoras que os/as fazem carecer de ser de si mesmos/as e, enfim, até adoecer...

Também não vão nos faltar pesquisas sobre a desmotivação dos docentes (JESUS, 2002), sobre as complicações de suas condições de saúde diante da precarização do trabalho (GASPARINI, 2005; DELCOR, 2003), sobre seu mal-estar (ESTEVE, 1999) em tempos de crise da educação escolar... Mas, "professora, e o que dá para fazer" - pergunta angustiada uma aluna? E se destituíssemos dessas ilusões e instalássemos, em seu lugar, uma ciência, uma filosofia, uma psicanálise, uma política de formações de 
professores? Estaríamos simplesmente criando outras ilusões, outros sermões, desde que ao Professor de Ciências continuasse a ser atribuído um caráter ilusório. Deixemos, então, de tomar a Docência em Ciências como uma ilusão... Mas não é perigoso para a educação em Ciências? 0 mundo da Educação em Ciências não ruiria? 0 que faríamos nós sem essa ilusão? Podemos prescindir do embotamento anestesiante da ilusão e, mesmo assim, continuar formando professores de Ciências?

Ao situar a Ciência e o discurso pedagógico do Ensino de Ciência no estatuto de verdade, para além do bem e do mal, criou-se a autoridade inquestionável da docência em Ciências, reduziu-se a política de formação de professores a uma questão de crise moral dos valores contemporâneos e as dificuldades da vida coletiva. Confiamos num processo que se dá por descobertas. Compramos rotas para o futuro, cápsulas que extenuam nosso amanhã, a par de sermos tão gentilmente nós mesmos. Parece-nos que chegou o tempo de des-iludir radicalmente essa ilusão e tomarmos outra direção. Entretanto, há uma tarefa prévia: aproveitar, na educação dos educadores em Ciências, uma re-educação, que nos leve à desfragmentação do Eu único, centrado e soberano (CORAZZA, 2006). Re-educação que nos distancie dos saberes derivados da ilusão-da-docência-em-Ciências, manifestados no ideário pedagógico hegemônico do Ensino de Ciências, que coage nossa atividade e curiosidade intelectual em relação à docência.

Renegar o discurso pedagógico totalitário que só inibe o pensamento e nos faz repetir as suas crenças-de-docência, suas crenças-de-ciência, suas crenças-de-pedagogia. Re-educar os educadores implica dessacralizar o professor de Ciências Salvador e Aperfeiçoador do ser humano, o professor "profeta capaz de falar do deserto e de contar o que sabe de um povo por vir; por construir" (NEGRI, 2001, p. 23). Mas, que antes de anunciar a possibilidade do novo, "procura viver as situações e dentro dessas situações vividas produzir a possibilidade do novo, [...] aque- 
le que age coletivamente para tocar a cada um dos indivíduos" (GALLO, 2003, p. 74). Descolar-nos de todas as identificações com os docentes-ilusórios, deixar de demandar que sejam a nossa superpotência imaginária, que os deixam, e a nós próprios, sem possibilidade de aflorar o novo na pele. Reconhecer que a docência-ilusão-de-Ciências existe e funciona, porém, dizer que nela não acreditamos mais. Isso vai nos levar, certamente, à incerteza subjetiva e à não satisfação de nossa vontade de saber/ poder sobre um professor de Ciências, agora, desconhecido/a. Afinal, uma das tarefas fundamentais da prática da liberdade consiste justamente naquilo que nos lembra Foucault (2006), em não aceitar jamais algo como definitivo, intocável, imóvel, óbvio, em pensar de outro modo.

\section{Trans-migrar a docência em Ciências}

Trazemos, aqui, o poeta Oliveiro Girondo, para contar que o que nos interessa nessa espécie de des-formação de professores de Ciências é a transmigração (GIRONDO, 1999). Por mais que nossos cérebros tentem, jamais compreendemos porque devemos passar a vida inteira no mesmo esqueleto. Porque não amanhecer em um ipê para sentir o vento, dormir dentro de um amonóide fóssil ou passar a noite como um espírito de gato ou coruja? Porque não ser terra para sentir-se penetrado por tubérculos e raízes, por uma vida que nos fecunda e até faz cócegas? Não seria interessante ser porco para saber-se presunto? Ser cavalo para, aí sim, "puxar a carroça"? Como deve ser contemplar o mar com olhos de caranguejo? Ruminar no campo personificado em vaca? Ou cantar para as estrelas com a voz de um sapo? Quão não será surpreendente desprender-se do seu rabo para reconstituí-lo no próximo instante? Ah, qual será o encanto de ser um boto cor de rosa? De sentir a fundo a preguiça das preguiças ou metamorfose dos camaleões? De sorver o pólen das orquídeas como uma abelha? Como é possível não experimentar os espasmos de uma barata ou de uma samambaia? De ser urubu, formiga e por 
um ovo? De cair maduro do pé como uma maçã, manga, jaca e, enfim, apodrecer?

A transmigração explode dentro da terra da Ciência que construída de novidades iluministas, de seu humanismo fascista, forçou e modelou pela imposição de suas verdades certa forma de conhecimento e sua respectiva Humanidade. No ápice de seu altar hierárquico e excludente promoveu uma compreensão de conhecimento fracionário, moralmente individualista e autoritariamente copista. Copia, recorta e cola em cima do que já está pronto. Arremeda e não remexe. Coagula e não desliza, não cria nada de novo. A dureza e a rigidez da Ciência Moderna nos fizeram descrer do lado mágico, do criativo, do inventivo. Fizeram-nos pausar na segurança e na promessa dos métodos, enclausuram a forças no "eu-professor-de-Ciências" para ensinarmos apregoando modelos, pregando verdades. 0 que nos inquieta é, justamente, a possibilidade de abertura dos currículos de formação de professores em Ciências a transmigração para novos espaços híbridos, grávidos de tensões que possam articular sonhos com a vida. Sem ser alheia ou contrária a contribuição dos estímulos que provém de uma sociedade altamente consumista, tecnologicamente pragmática e copista, a transmigração quer falar da alma e da lama, das linhas de fuga e daquilo que elas tramam. Seu conhecimento é arte que se faz da vida (CUNHA, 2002). Para transmigrar a docência em Ciências, o que importa não é a forma final, o ser-professor, o saber-docente, importa o que não tem nenhuma forma, o que estranho a toda forma.

Transmigrar nos currículos de formação de professores de Ciências é querer mexer com a vulnerabilidade de um modo de pensar que não consegue deixar de ser caça de um caçador que ele mesmo arquiteta e institui. Não se ensina, entretanto, ninguém ou coisa alguma a transmigrar, só se pode viver a transmigração como aprendiz, partindo das relações banidas dos currículos. Transmigrar é potencializar e tomar a sala de aula num outro sentido, tornando-a um espaço da vida. Feito isso, talvez, pos- 
samos continuar educando educadores em Ciências, de modo a transformar a nossa miséria neurótica de educadores, nosso delírio viciante e viciado em ilusões identitárias, em apenas uma infelicidade banal. Porém, se tudo isso fracassar, como é de se esperar, de modo mais alegre e leve: não residamos na angústia ou na tristeza; nem na queixa ou no ressentimento; tampouco, nas soluções morais para a dor e a nostalgia de infinito. Transmigremos sem cansar. Aliás, mesmo porque, nenhuma das ilusões inventadas por nós da Educação em Ciências parece ter vida longa. Afinal, o para sempre, sempre acaba...

\section{Referências Bibliográficas}

AMORIM, Antônio Carlos Rodrigues. Roteiros em Ação: multiplicidades na produção de conhecimentos escolares. In: LOPES, Alice Ribeiro; MACEDO, E. (Org.). Currículo de Ciências em debate. Campinas: Cortez, 2004. p. 157-190.

AMORIM, Antônio Carlos Rodrigues. Os olhares do caminhante nos territórios do ensino de Biologia. Tese (Doutorado em Educação). Faculdade de Educação/UNICAMP, Campinas, 2000.

AMORIM, Antônio Carlos Rodrigues. Imagens e narrativas entrecortando a produção de conhecimentos escolares. Educação e Sociedade, São Paulo, 2004 , v. 25, n. 86, p. 37-54.

AMORIM, Antônio Carlos Rodrigues. Invisível e não enunciável: cinema brasileiro e amnésia de identidades. Educação e Sociedade, São Paulo, 2006, v. 27, p. 1367-1372.

ANDRÉ, Marli. (org). Formação de professores no Brasil (1990-1998). Brasília: MEC/Inep/Comped, 2002.

AZEVEDO, Maria Cristina P. Stella. Ensino por investigação: problematizando as atividades em sala de aula. In: CARVALHO, Ana Maria Pessoa de. (Org.). Ensino de Ciências: unindo a pesquisa e a prática. São Paulo: Pioneira, 2004.

BALL, Sthepen. Profissionalismo, gerencialismo e performatividade. Cadernos de Pesquisa, São Paulo, set./dez 2005, v. 35 n. 126.

BERNADETTI, Sandra Cristina Gorni. Entre a educação e o plano de pensamento de Deleuze \& Guattari: uma vida...Tese (Doutorado). USP, Faculdade de Educação, São Paulo, 2007. 
BIZZO, Nélio Ciências: fácil ou difícil? São Paulo: Ática, 1998.

BROCKMAN, John. Einstein, Gertrude Stein, Wittgenstein e Frankenstein: reinventando o universo. São Paulo: Companhia das Letras, 1988.

CARRASCOSA, Jaime. Análise da formação continuada e permanente dos professores de Ciências Ibero-Americanos. In: MENEZES, Luiz Carlos. Formação Continuada de Professores de Ciências no Contexto Ibero-americano. Campinas, Ed. Autores Associados, 1996. p. 7-44.

CARVALHO, Ana Maria Pinto de; GIL-PÉREZ, Daniel. A formação de professores de Ciências: tendência e inovações. São Paulo: Cortez, 1993.

CORAZZA, Sandra Mara. Na diversidade cultural, uma docência artística. Porto Alegre, Pátio - Revista Pedagógica, 2001, ano V, n.17, maio/julho. p.27-30.

COSTA, Luciano Bedin da; CUNHA, Carla Madruga Professor/a infernizando na aula de metodologia científica (com Nietzsche, Deleuze e outros malditos). Prâksis (Novo Hamburgo), 2006, v. 1, p. 53-58.

COSTA, Gilcilene Dias. Trilogia antropofágica [a educação como devoração]. Tese (Doutorado). Universidade Federal do Rio Grande do Sul, Porto Alegre, 2008.

CUNHA, Carla Madruga. (2002). A professora rizoma: TPM e magia na sala de aula. Dossiê Gilles Deleuze. Educação e Realidade, Porto Alegre, jul./dez 2002, v.27 n.2 p.157-168.

DELCOR, Núria Serre. Condições de trabalho e saúde dos professores da rede particular de ensino em Vitória da Conquista. Dissertação (Mestrado). Curso de Pós-Graduação em Medicina e Saúde, Universidade Federal da Bahia, 2003.

DELEUZE, Gilles. Conversações. Rio de Janeiro: Ed.34, 1992.

DELEUZE, Gilles; GUATTARI, Félix. Kafka: por uma literatura menor. Rio de Janeiro: Imago, 1977.

DELEUZE, Gilles; GUATTARI, Félix. Mil Platôs: capitalismo e esquizofrenia. Rio de Janeiro: Ed. 34, 1997a.

DELEUZE, Gilles; GUATTARI, Félix. $\mathbf{0}$ que é a filosofia? Rio de Janeiro: Editora $34,1997 \mathrm{~b}$.

DELEUZE, Gilles; GUATTARI, Félix. Foucault. São Paulo: Brasiliense, 2006.

DERRIDA, Jacques. A farmácia de Platão. São Paulo: Iluminuras, 1991.

DERRIDA, Jacques. 0 animal que logo sou. São Paulo: UNESP, 2002. 
ESTEVE, José Maria. 0 mal-estar docente: a sala de aula e a saúde dos professores. $2^{\underline{a}}$ ed. EDUSC: São Paulo, 1999.

FREITAS, Denise de; VILLANI, Alberto. (2009) Formação de professores de Ciências: um desafio sem limites. Investigações em Ensino de Ciências (Online), Porto Alegre, 2002, v.7, n.3, p. 25-37.

FOUCAULT, Michel. Arqueologia do saber. Rio de Janeiro: Forense Universitária, 1986.

FOUCAULT, Michel. As palavras e as coisas: uma arqueologia das Ciências humanas. 8. ed. São Paulo: Martins Fontes, 1999.

FOUCAULT, Michel. Verdade e subjetividade. Rev. de Com. e Linguagem. Lisboa. 1993, n.19. p. 203-223.

FOUCAULT, Michel. Vigiar e punir. Petrópolis, RJ: Vozes, 1987.

FOUCAULT, Michel. Estratégia poder-saber. Rio de Janeiro: Forense Universitária, 2006. Coleção Ditos e escritos, v. 4.

FOUCAULT, Michel. Segurança, Território e População. São Paulo: Martins Fontes, 2008.

FISCHER, Rosa Maria Bueno. 0 estatuto pedagógico da mídia: questões de análise. Educação e Realidade, Porto Alegre, 1997, v. 22, n. 2, p. 59-79.

GALLO, Silvio. Deleuze \& a Educação. Belo Horizonte: Autêntica, 2003.

GARCIA, Carlos Marcelo. Pesquisas sobre formação de professores: o conhecimento sobre aprender a ensinar. Revista Brasileira de Educação, set/dez 1998, n. 9, p. 51-75.

GARCIA, Joao Eduardo; PORLÄN, Rafael. Ensino de Ciências e prática docente: uma teoria do conhecimento profissional. Caderno pedagógico, UNIVATES, jul/dez. 2000, n. 3, p. 7-42.

GASPARINE, Sandra Maria; BARRETO, Sandhi Maria; ASSUNÇÃO, Ada Ávila. O professor, as condições de trabalho e os efeitos sobre sua saúde. Educação e Pesquisa. São Paulo, maio/ago 2005, v. 31, n.2, p. 189-199.

GAUTHIER, Clermont. Esquizoanálise do currículo. Dossiê Gilles Deleuze. Educação e Realidade, Porto Alegre, 2002, v.27 n.2 p.143-155, jul./dez.

GIRONDO, Oliveiro. Transmigración. In: ANTELO, Roberto. (coord). Obra completa / Oliviero Girondo: edição crítica. Barcelona: ALLCA XX, Universidade de Paris X, 1991. GUATTARI, Félix. 0 inconsciente maquínico: ensaios de esquizoanálise. Campinas: Papirus, 1988. 
HARAWAY, Donna. Saberes localizados. Cadernos Pagu, 1995, n. 5, p. 01- 47. HARDT, Michel; NEGRI, Antonio. Império. São Paulo: Record, 2001.

HARTLEY, David. Re-schooling society. (1997) Washington: The Falmer Press.

JESUS. Saul Neves. Desmotivação e crise da identidade na profissão docente. Katály, Florianópolis, 2004, jul./dez, v. 7 n. 2, p. 192-202.

KLIEBARD, Hebert. Forging the american curriculum. Londres: Routledge, 1992.

KRASILCHIK, Miriam. Prática de Ensino de Biologia. 4aㅡ ed. São Paulo: EDUSP, 2004. KOHAN, Walter. Entre Deleuze e a Educação: notas para uma política do pensamento. Dossiê Gilles Deleuze. Educação e Realidade, Porto Alegre, 2002, v.27 n.2 p.123-130 jul./dez.

KROEF, Ada Beatriz Gallichio. Currículo nômade: sobrevôos de bruxas e travessias de piratas. Tese (Doutorado). UFRGS, Faculdade de Educação, Porto Alegre, 2003.

LOPES, Eliante Marta Teixeira. Da sagrada missão pedagógica. Tese apresentada para concurso de professor titular. Faculdade de Educação, UFMG, Belo Horizonte, 2004.

LUDKE, Menga; BOING, Luiz Alberto. Caminhos da profissão e profissionalidade docente. Educação \& Sociedade, 2004, v. 25, n. 89; p. 1159-1180.

MACHADO, Arlindo. Pré-cinemas e pós-cinemas. Campinas: Papirus, 1997.

MALDANER, Otavio Aloisio. A formação inicial e continuada de professores de química. Ijuí: UNIJUÍ, 2000.

MARCELO, Carlos. Formação de Professores - para uma mudança educativa. Barcelona: Porto Editora, 1999.

MARCELO, Carlos. Pesquisa sobre a formação de professores: o conhecimento sobre aprender a ensinar. Revista Brasileira de Educação, 1998, n. 9, p. 51-75.

MEDEIROS, Arilene Maria Soares. Formação de professores sob a perspectiva da teoria crítica e das políticas educacionais. Educação e Linguagem, 2005, v. 8, n. 11, p. 195-210.

MORAES, Roque. 0 significado da experimentação numa abordagem construtivista: o caso do ensino de Ciências. In: BORGES, Regina; MORAES, Roque. Educação em Ciências nas áreas iniciais. Porto Alegre: Sagra-Luzzalto, 1998.

NÓVOA, Antonio. Formação de professores e profissão docente. In: NÓVOA, Antonio. (coord.). Os professores e a sua formação. Lisboa: Publicações Dom Quixote, 1992. 
OLIVEIRA, Thiago Ranniery Moreira. Mapas dança desenho: a cartografia como método de pesquisa em educação. In: MEYER, Dagmar;; PARAÍSO, Marlucy Alves. Metodologias de pesquisas pós-críticas em educação. Belo Horizonte: Mazza Edições, 2012. p. 279-304.

PAGOTTO, Maria Dalva. A organização das licenciaturas: práticas atuais e perspectivas de mudanças. Anais do IX ENDIPE, 1998, p. 376-384.

PARAÍSO, Marlucy Alves. Currículo e Diferença. In: PARAÍSO, Marlucy Alves. (org). Pesquisas sobre culturas e currículos. Curitiba: Editora CRV, 2010.

PARAÍSO, Marlucy Alves. Currículo e mídia educativa brasileira: poder, saber e subjetivação. Chapecó: Argos, 2007.

PARAÍSO, Marlucy Alves. Política da subjetividade docente no currículo da mídia educativa brasileira. Educação e Sociedade, Campinas, 2006, v. 27, n. 94, p. 91-115.

PARAÍSO, Marlucy Alves. Diferença em si no currículo. In: 28a. Reunião Anual da ANPED, 2005, Caxambu. Anais... Caxambu: ANPEd, 2005a, p. 1-17.

PARAÍSO, Marlucy Alves. Currículo-mapa: linhas e traçados das pesquisas pós-críticas sobre currículo. Educação e Realidade, Porto Alegre, 2005b, v. 30, n. 1, p. 67-82.

PARAÍSO, Marlucy Alves. 0 auto-gerenciamento de docentes em sua formação e em seu trabalho. Educação e Pesquisa, São Paulo, 2005c, v. 31, n. 2, p. 173-188.

PARAÍSO, Marlucy Alves. Pesquisas pós-críticas em educação no Brasil: esboço de um mapa. Cadernos de Pesquisa, São Paulo, 2004, v. 34, n. 122, p. 283-303. PEREIRA, Júlio Emílio Diniz. Formação de professores: pesquisa, representações e poder. Belo Horizonte: Autêntica, 2000.

ROCHA FILHO, Joao Bernardes. Observando a física da não-linearidade em um experimento simples. Caderno Brasileiro de Ensino de Física. v. 24, n. 2. Florianópolis, ago. 2007. p. 224-232.

ROLNIK, Suely. Cartografia Sentimental: transformações contemporâneas do desejo. São Paulo: Estação Liberdade, 1989.

ROSE, Nicolas. Inventando nosso eus. In: SILVA, Tomaz Tadeu. (org). Nunca fomos humanos: nos rastros do sujeito. Belo Horizonte: Autêntica, 2001.

RORTY, Richard. Philosophy and the mirror of nature. Princeton, New Jersey: Princeton University Press, 1979.

ROY, Kaustuv. Gradientes de intensidade: o espaço háptico deleuziano e os três "erres" do currículo. Dossiê Gilles Deleuze. Educação e Realidade, jul./dez 2002, Porto Alegre, v.27 n.2, p.67-76.

SANTOS, Lucíola. Formação de professores na cultura do desempenho. Educação e Sociedade, 2004, vol.25 n.89 Campinas sept./dec. 


\section{À FLOR DA PELE: UMA CARTOGRAFIA DA SUBJETIVIDADE DOCENTE EM CIÊNCIAS}

SCHAMA, Simon. Paisagem e Memória. São Paulo: Companhia das letras, 1996. SCHNETZLER, Roseli Pacheco. (2000) O professor de Ciências: problemas e tendências de sua formação. In: SCHNETZLER, Roseli Pacheco; ARAGÃO, Rosália. (orgs.). Ensino de Ciências: fundamentos e abordagens. Piracicaba: CAPES/UNIMEP.

SCHON, Donald. A Formar professores como profissionais reflexivos. . In: NOVOA, Antonio. (org) Os professores e sua formação. Lisboa: Dom Quixote, 1995.

SCHON, Donald. The Reflective Practitioner: how professionals think in action. Basic Books, New York, 1993.

SENNETT, Richard. 0 declínio do homem público: as tiranias da intimidade. São Paulo: Companhia das Letras, 1988.

SIMON, Roger. A pedagogia como uma tecnologia cultural. In: SILVA, Tomaz Tadeu. (Org.). Alienígenas na sala de aula: uma introdução aos estudos culturais em educação. 5. ed. Petrópolis: Vozes, 2003. p. 61-84.

SILVA, Tomaz Tadeu. $\mathbf{O}$ currículo como fetiche: a poética e a política do texto currícular. Belo Horizonte: Autêntica, 1999.

TARDIF, Maurice. Saberes profissionais dos professores e conhecimentos universitários: elementos para uma epistemologia da prática profissional dos professores e suas conseqüências em relação à formação para o magistério. Revista Brasileira de Educação. ANPED, 2000, n. 13, p. 5-24.

TEIXEIRA, Paulo Marcelo Marini; MEGID NETO, Jorge. Pesquisa em ensino de Biologia no Brasil (1972-2004): um estudo com base em dissertações e teses. VII Encontro Nacional de Pesquisa em Ensino de Ciências. Florianópolis: Universidade Federal de Santa Catarina. Anais. Florianópolis: ABRAPEC, 2007.

VASQUEZ, Adolfo Sanchéz. Filosofia da praxis. Rio de Janeiro: Paz e Terra, 1968. VEIGA-NETO, Alfredo. Olhares... In: COSTA, Marisa Vorraver. (org.) Caminhos Investigativos. Novos olhares na pesquisa em educação. $2^{\underline{a}}$ Ed. Rio de Janeiro: DP\&A, 2002.

WEISSMANN, Hilda. Didática das Ciências Naturais: contribuições e reflexões. Porto Alegre: Artes Médicas, 1998.

Recebido em 02.03.2013

Aprovado em 23.05.2013 